\title{
Clinical impact of PSMA PET in biochemically recurrent prostate cancer; a review of the literature
}

\author{
Maurits Wondergem · Friso M. van der Zant · Wouter A. M. Broos · Remco J. J. Knol
}

Published online: 11 August 2020

(C) The Author(s) 2020

\begin{abstract}
PSMA PET is increasingly used for localising biochemical recurrent prostate cancer (BCR) and is incorporated in European and national guidelines. Nevertheless, clinical implications of PSMA PET need to be clarified. In this report, the available literature on the clinical impact of PSMA PET in patients with BCR is reviewed. A comprehensive literature search was performed using the MEDLINE ${ }^{\circledR}$ database. All studies reporting data on PSMA PET directed patient management were considered relevant. In the review, 16 studies were included. Change of management was $45 \%$ for the pooled data (861/1899 patients), of which $50 \%$ changed from non-targeted to targeted approach. Change from targeted to non-targeted approaches was found in $17 \%$ of patients. High heterogeneity was found between presently available studies. It can be concluded that PSMA PET induces change of management in almost half of the patients with BCR. After PSMA PET more patients are selected for metastasis targeted therapies. Potential beneficial effects of metastasis directed therapies require further evaluation.
\end{abstract}

Keywords prostate cancer $\cdot$ prostate specific membrane antigen $\cdot$ PSMA PET $\cdot$ biochemical recurrence

\section{Klinische waarde van PSMA PET bij biochemisch recidiefprostaatcarcinoom; een review van de literatuur}

Samenvatting PSMA PET wordt steeds vaker gebruikt voor het lokaliseren van biochemisch recidiefprostaatkanker (BCR). Het gebruik ervan is opgenomen in Europese en nationale richtlijnen. Desondanks zijn de klinische implicaties van PSMA PET onduidelijk. In deze review wordt de beschikbare literatuur over de klinische impact van PSMA PET bij patiënten met BCR besproken. Met behulp van de MEDLINE ${ }^{\circledR}$-database werd een literatuuronderzoek uitgevoerd, waarbij artikelen zijn geïncludeerd die gegevens over therapeutische consequenties van PSMA PET bij BCR rapporteerden. In de review werden 16 artikelen opgenomen. Uit de gepoolde data bleek dat het beleid op grond van PSMA PET was aangepast bij $45 \%$ van de patiënten (861/1899), waarbij in $50 \%$ van de gevallen het beleid veranderde van niet-gerichte naar op metastasen gerichte behandeling. Verandering van gerichte naar niet-gerichte behandeling werd gevonden bij $17 \%$ van de patiënten. De beschikbare studies waren sterk heterogeen. De conclusie is dat PSMA PET bij bijna de helft van de patiënten met BCR leidt tot wijziging van het behandelbeleid. Na PSMA PET worden meer patiënten geselecteerd voor op metastasen gerichte behandelingen. Potentieel gunstige effecten van deze behandelingen dienen verder in kaart te worden gebracht.

Trefwoorden prostaatkanker · prostaatspecifiek membraanantigeen $\cdot$ PSMA PET $\cdot$ biochemisch recidief 


\section{Introduction}

Prostate cancer ( $\mathrm{PCa}$ ) is the most common cancer in men in the Western world [1, 2]. Between $28 \%$ and $53 \%$ of patients treated with curative intention will develop biochemically-recurrent prostate cancer (BCR) [3]. BCR is defined as two consecutive prostatespecific antigen (PSA) values $\geq 0.2 \mathrm{ng} / \mathrm{mL}$ after radical prostatectomy, or any PSA increase of $2.0 \mathrm{ng} / \mathrm{ml}$ above the nadir following radiation therapy and brachytherapy, however in recent clinical trials other definitions have been applied [4-6]. Accurate imaging studies are desired for patients with BCR as early lesion localisation directs further treatment, which might include stereotactic metastasis-directed radiotherapy, salvage radiotherapy, salvage lymph-node dissection, or the initiation of systemic treatment [3].

Since more than a decade, positron emission tomography (PET) is one of the cornerstones of oncologic imaging and has been proven useful for a large variety of malignancies. However, the most frequently used tracer $\left[{ }^{18} \mathrm{~F}\right]$-fluorodeoxyglucose $\left(\left[{ }^{18} \mathrm{~F}\right]-\mathrm{FDG}\right)$ has a relatively low sensitivity for prostate cancer and therefore PET has had little impact on prostate cancer imaging and patient management, until recently [7]. In the last decade, the introduction of $\left[{ }^{18} \mathrm{~F}\right]-\mathrm{flu}-$ orocholine and $\left[{ }^{11} \mathrm{C}\right]$-choline PET has proven useful for detection and localisation of prostate cancer. In clinical practice it was used especially for detection of a biochemical relapse after therapies with curative intent. The relatively low positive predictive values of $\left[{ }^{18} \mathrm{~F}\right]$-fluorocholine and $\left[{ }^{11} \mathrm{C}\right]$-choline, particularly due to false positive inflammatory lymph nodes, has prevented the wide clinical use of those tracers in primary staging of prostate cancer. Another known drawback of choline tracers is the moderate sensitivity for lymph node metastases [8].

Lack of specificity of conventional imaging techniques has encouraged researchers to screen prostate cancer cells for suitable antigens in order to develop agents capable of specific binding. This resulted in the development of monoclonal antibodies (mAbs) to target prostate specific antigen (PSA) and prostatic acid phosphatase (PAP) [9]. Secretion of those antigens preclude cell-associated binding and presence of PSA and PAP in the plasma effectively blocks specific antibody binding at the tumour site. Thereafter, prostate specific membrane antigen (PSMA) was discovered, which is a 750 amino acid transmembrane protein and a highly specific prostate epithelial cell membrane antigen [10, 11]. Physiological expression of PSMA in normal cells is 100-1000 fold less than baseline expression in prostate cancer, expression increases as tumour grade increases with concurrent increase in metastatic sites and castrate refractory prostate cancer (CRPC) [7, 8]. Furthermore, PSMA is internalised and endosomally recycled, which increases the deposition of radiopharmaceuticals into the cell over time [9].
In 2006, ${ }^{111}$ In-capromab, a mAb for targeting PSMA, was reported. However, this tracer has a poor efficacy associated with binding to the intracellular domain of PSMA, resulting in binding to nonviable cells that have damaged cell membranes only [10]. A few years later, mAbs targeting the external domain of PSMA were reported. Due to their relatively large mass, these ligands show slow clearance from background and slow target recognition, prohibiting their success as radiopharmaceuticals for imaging. Furthermore, they require superior safety profiles, since mAbs have potential side effects including allergic reactions [11-13]. From the late 2000s small molecule PSMA inhibitors, which are approximately 350 fold smaller than mAbs, have been reported [14-17]. Those tracers have rapid target recognition and background clearance and no adverse effects have been reported.

In comparison with choline, these PSMA-tracers have shown to detect more lesions at lower PSA levels, which not only increases the sensitivity for prostate cancer, but also increases the clinical impact of PET in prostate cancer $[17,18]$. Furthermore, the specific binding to PSMA increases specificity for prostate cancer and positive predicting values.

At present, several PSMA tracers are available for clinical use including tracers labelled with ${ }^{68} \mathrm{Ga}$ or ${ }^{18} \mathrm{~F}$. ${ }^{18} \mathrm{~F}$-labeled tracers have some potential benefits since positrons emitted by ${ }^{18} \mathrm{~F}$ decay have lower kinetic energies compared to those emitted by ${ }^{68} \mathrm{Ga}$, resulting in a higher resolution of PET images acquiring ${ }^{18} \mathrm{~F}$ tracers. Furthermore, the 110 min half-life of ${ }^{18} \mathrm{~F}$ compared to $68 \mathrm{~min}$ half-life for ${ }^{68} \mathrm{Ga}$, enables imaging at later timepoints without significant deterioration of image quality or the need for administration of higher dosages. However, for both ${ }^{68} \mathrm{Ga}$ and ${ }^{18} \mathrm{~F}$ labelled tracers, high detection rates are reported in literature (Tab. 1; [19-23]). As a result, PET imaging with PSMA tracers for prostate cancer has found its way into standard clinical practice and is already incorporated in European and national guidelines (https:// uroweb.org/guideline/prostate-cancer/and https:// richtlijnendatabase.nl/richtlijn/prostaatcarcinoom/ diagnostiek/beeldvormend_onderzoek/psma_pet_ct_ bij_prostaatcarcinoom.html). The Dutch guidelines recommend the use of PSMA PET when screening for metastases in primary staging is indicated and for detection of BCR after radical prostatectomy and radiation therapy. Nevertheless, clinical implications of PSMA PET need to be clarified. Therefore, in this report, the available literature on the clinical impact of PSMA PET in patients with BCR has been reviewed.

\section{Methods}

\section{Identification of studies}

A comprehensive literature search was performed using the MEDLINE ${ }^{\circledR}$ database to identify relevant studies by the following strategy: ('rostate"' [MeSH Terms] 
Table 1 Detection rates of different PSMA tracers for biochemical recurrent prostate cancer

\begin{tabular}{|c|c|c|c|c|c|c|c|c|}
\hline \multirow[t]{2}{*}{ Author } & \multirow[t]{2}{*}{ Year } & \multirow[t]{2}{*}{ Publication type } & \multirow[t]{2}{*}{ Tracer } & \multirow[t]{2}{*}{ N } & \multicolumn{4}{|c|}{ Detection rates (\%) per PSA category (ng/ml) } \\
\hline & & & & & $<0.5$ & $0.5-1.0$ & $1.0-2.0$ & $>2.0$ \\
\hline Giesel et al. [19] & 2018 & Original article & {$\left[{ }^{18}\right.$ F]-PSMA-1007 } & 251 & 62 & 74 & 91 & 94 \\
\hline Mena et al. [20] & 2019 & Original article & {$\left[{ }^{18} \mathrm{~F}\right]-\mathrm{DCFPyL}$} & 90 & 48 & 50 & 89 & 94 \\
\hline Perera et al. [21] & 2019 & Meta-analysis & {$\left[{ }^{68} \mathrm{Ga}\right]-\mathrm{PSMA}-11$} & 4790 & 45 & 59 & 75 & 95 \\
\hline Rahbar et al. [22] & 2018 & Original article & {$\left[{ }^{18} \mathrm{~F}\right]-\mathrm{PSMA}-1007$} & 100 & 86 & 89 & 100 & 100 \\
\hline Song et al. [35] & 2019 & Original article & {$\left[{ }^{18} \mathrm{~F}\right]-\mathrm{DCFPyL}$} & 72 & 50 & 69 & 100 & $91-96$ \\
\hline Wondergem and Jansen et al. [23] & 2019 & Original article & {$\left[{ }^{18} \mathrm{~F}\right]-\mathrm{DCFPyL}$} & 248 & 59 & 69 & 85 & 96 \\
\hline
\end{tabular}

OR "prostate'"[All Fields]) AND ('neoplasms"'[MeSH Terms] OR "neoplasms"'[All Fields] OR "cancer',[All Fields]) AND biochemical[All Fields] AND ('recurrence'" [MeSH Terms] OR 'recurrence',[All Fields]) AND PET[All Fields]. The limit "humans" was used. The reference list of potential suitable studies was additionally searched to identify other relevant studies. This resulted in 535 potentially relevant studies.

\section{Inclusion and exclusion criteria}

All abstracts of relevant studies were reviewed with a set of predefined inclusion and exclusion criteria. All studies reporting data on PSMA PET directed patient management were considered relevant. No language restrictions were applied. The following studies were excluded from this review: studies presenting data on a patient population that was suspected to be used in earlier publications; studies of which no full text article was available; review studies; letters to the editor and case reports. This resulted in 36 included studies.

\section{Data extraction}

After initial assessment for inclusion the following data were extracted from the selected studies: study design, aim of the study, number of included patients; used PSMA tracer, used definition of biochemical recurrence, inclusion criteria, previous therapies, PSA at time of PET, number of patients with PET induced change in management, and kind of change in management. An additional 20 studies were excluded based on the extracted data: 15 did not report numbers on change of management, three studies also included patients with PSA persistence after radical prostatectomy and two studies also included patients with primary prostate cancer. For two studies it could not be ruled out that patients with PSA persistence were included; however, since inclusion of those patients was not mentioned explicitly, those studies were included in the further analysis.

\section{Data structuring}

PSMA PET induced change in management was divided in nine groups: systemic to targeted therapy, surveillance to targeted therapy, change of targeted strategy, targeted to systemic therapy, surveillance to systemic therapy, change of systemic therapy, targeted therapy to surveillance, systemic therapy to surveillance, and others. The data of studies that provided sufficient data to extract the exact numbers of change in therapy were pooled. Targeted therapies included: prostatectomy, lymph node dissection, local radiation therapy, pelvic lymph node radiation, and stereotactic radiation of oligometastatic disease.

\section{Results}

Ultimately 16 studies were included in the review (Tab. 2; [24-39]). Twelve studies reported outcomes using $\left[{ }^{68} \mathrm{Ga}\right]-P S M A-11$ PET, while four studies reported data on other PSMA-tracers. 14 studies used PET combined with computed tomography (CT), while two studies also included patients that received PET combined with magnetic resonance imaging (MRI). Large differences were found between included patient populations, including: patients with low PSA values versus patients without limitations for PSA values, oligometastatic disease on PSMA PET versus no restriction of number of metastases, only radical prostatectomy as previous therapy versus all kinds of previous therapies, normal or equivocal findings on conventional imaging before PSMA PET versus no restrictions on findings on previous imaging, and inclusion of patients found suitable for radiation therapy before PSMA PET versus patients without limitations on intended therapy before PSMA PET.

The reported rate of change of management ranged from $19-73 \%$ (Tab. 3). The pooled data of all patients included in this review show an overall change of management in 861 of 1899 patients (45\%). Nine studies, including 729 patients, reported sufficient data to extract the kind of change in management $[20,24,26$, $27,29,33,36,38,40]$. In 332 (46\%) of these 729 patients a change in management was seen. In $50 \%$ of them management changed to a targeted approach while systemic treatment or surveillance was scheduled without information from PSMA PET (Fig. 1). A change from targeted approaches to non-targeted was found in $17 \%$ of patients. As a result, PSMA PET directed more patients to targeted therapy strategies. 


\section{Artikel}

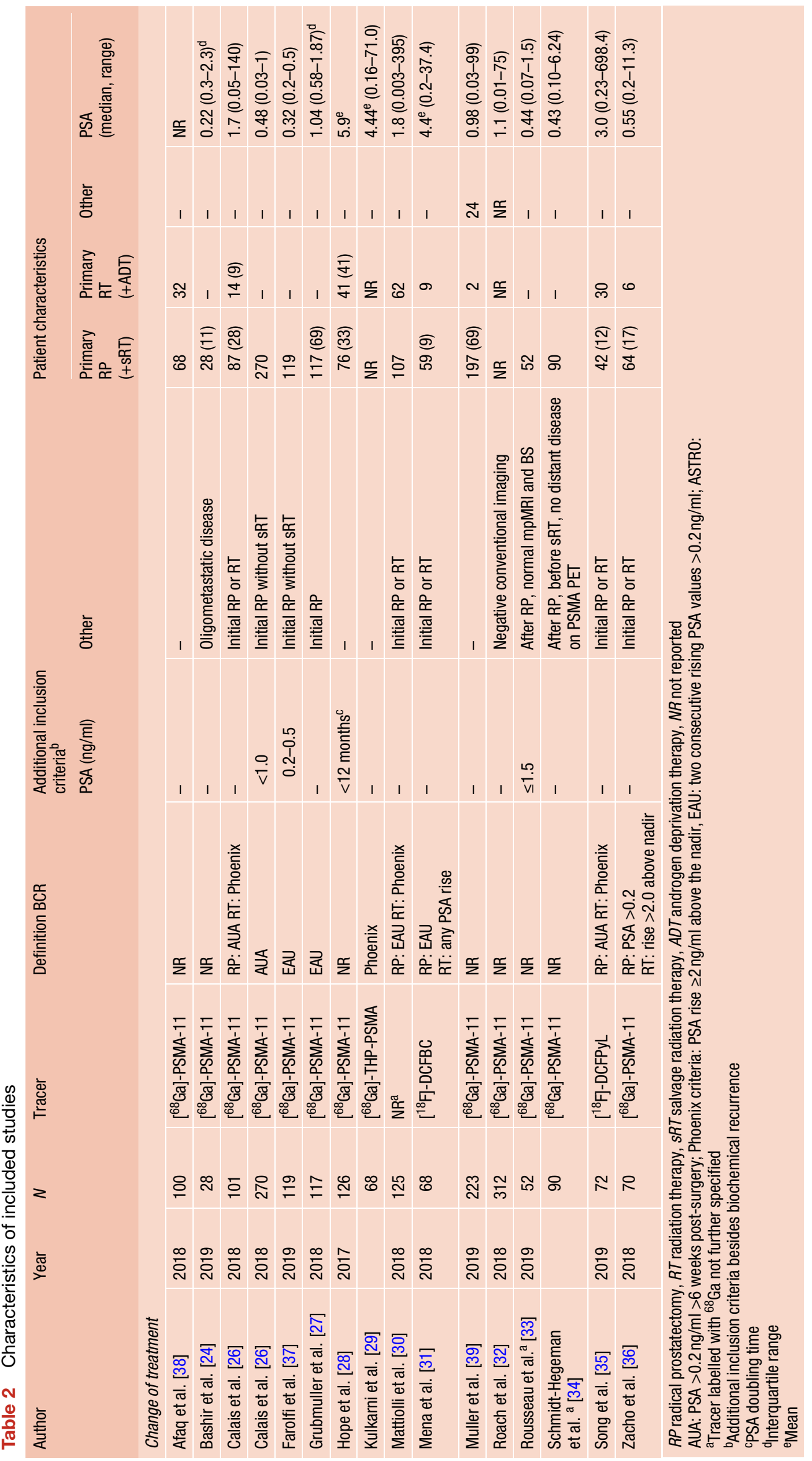




\title{
Hier staat een advertentie.
}

\author{
cef bohn \\ stafleu \\ van loghum
}

Houten 2020 


\title{
Hier staat een advertentie.
}

\author{
cef bohn \\ stafleu \\ van loghum
}

Houten 2020 
Table 3 Change of management after PSMA PET

\begin{tabular}{|c|c|c|c|c|c|c|c|c|c|c|c|c|c|}
\hline Afaq et al. [38] & 2018 & Retrospective & $39 / 100$ & $39 \%$ & 8 & 6 & 5 & 3 & 3 & 2 & 1 & 1 & 10 \\
\hline Bashir et al. [24] & 2019 & Retrospective & $12 / 28$ & $43 \%$ & - & 1 & 9 & 2 & - & - & - & - & - \\
\hline Calaiset al. [26] & 2018 & Prospective & $54 / 101$ & $53 \%$ & 12 & 9 & 8 & 6 & 7 & 5 & 4 & 3 & - \\
\hline Calais et al. [26] & 2018 & Retrospective & $52 / 270$ & $19 \%$ & NR & NR & NR & NR & NR & NR & NR & NR & NR \\
\hline Farolfi et al. [37] & 2019 & Retrospective & $36 / 119$ & $30 \%$ & 17 & NR & NR & NR & NR & NR & NR & NR & NR \\
\hline Grubmuller et al. [27] & 2018 & Retrospective & $50 / 117$ & $43 \%$ & 23 & 18 & 2 & - & - & 5 & 1 & 1 & - \\
\hline Hope et al. [28] & 2017 & Prospective & $67 / 126$ & $53 \%$ & 19 & 15 & 10 & 6 & 6 & 1 & 6 & 4 & - \\
\hline Kulkarni et al. [29] & 2019 & Prospective & $23 / 68$ & $34 \%$ & 2 & 1 & 3 & 4 & 2 & 6 & 4 & - & 1 \\
\hline Mattiolli et al. [30] & 2018 & Retrospective & $66 / 104$ & $63 \%$ & NR & NR & NR & NR & NR & NR & NR & NR & NR \\
\hline Mena et al. [31] & 2018 & Prospective & $34 / 68$ & $50 \%$ & - & 18 & - & - & 3 & - & 13 & - & - \\
\hline Muller et al. [39] & 2019 & Retrospective & $122 / 203$ & $60 \%$ & NR & NR & NR & NR & NR & NR & NR & NR & NR \\
\hline Roach et al. [32] & 2018 & Prospective & $192 / 312$ & $62 \%$ & NR & NR & NR & NR & NR & NR & NR & NR & NR \\
\hline Rousseau et al. [33] & 2019 & Prospective & $38 / 52$ & $73 \%$ & 9 & 13 & 8 & - & 2 & - & 4 & 2 & - \\
\hline Schmidt-Hegeman et al. [34] & 2019 & Retrospective & $18 / 90$ & $20 \%$ & NR & NR & NR & NR & NR & NR & NR & NR & NR \\
\hline Song et al. [35] & 2019 & Prospective & $43 / 72$ & $60 \%$ & NR & NR & NR & NR & NR & NR & NR & NR & NR \\
\hline Zacho et al. [36] & 2018 & Prospective & $15 / 69$ & $22 \%$ & 7 & 4 & 2 & 2 & - & - & - & - & - \\
\hline$N R$ not reported & & & & & & & & & & & & & \\
\hline
\end{tabular}

Seven studies did not report sufficient data to extract the kind of management change; those are reviewed in a narrative way in the following paragraphs. Farolfi et al. reported change in management in $36 / 119$ patients $(30 \%)$ as a secondary outcome in a study that assessed the performance of $\left[{ }^{68} \mathrm{Ga}\right]-$ PSMA-11 PET/CT in BCR after radical prostatectomy without salvage radiation therapy [37]. A similar study by Song et al. used the promising ${ }^{18} \mathrm{~F}$-labelled tracer ${ }^{18} \mathrm{~F}$-DCFPyL. They reported change of management in $43 / 72$ patients $(60 \%)$ in a heterogenous population of patients after RP and radiation therapy with BCR [35]. A study by Schmidt-Hegeman et al. primarily investigated the effect of $\left[{ }^{68} \mathrm{Ga}\right]-P S M A-11$ PET/CT guided radiation therapy on the biochemical recurrence free survival. They reported change in management in $18 / 90$ patients $(20 \%)$ with BCR who were scheduled for salvage radiation therapy before $\left[{ }^{68} \mathrm{Ga}\right]$-PSMA-11 PET/CT as a secondary finding [34].

A study by Roach et al. showed change in management in 192/312 patients (62\%) with BCR and negative or equivocal conventional imaging [32]. $\left.{ }^{68} \mathrm{Ga}\right]-$ PSMA-11 PET/CT resulted in a significant reduction in the number of men in whom the site of disease recurrence was unknown; besides there was significant increase in the detection of presumed oligometastatic and polymetastatic disease. In contrast to these results the authors reported no significant change in the intended overall treatment plan when categorized into surveillance, targeted/localized, or systemic therapy. However, since in this article those numbers are given only for the total population, changes in management for single patients cannot be extracted.

Fig. 1 Pooled data. Characteristics of change of management in $332 / 729$ patients

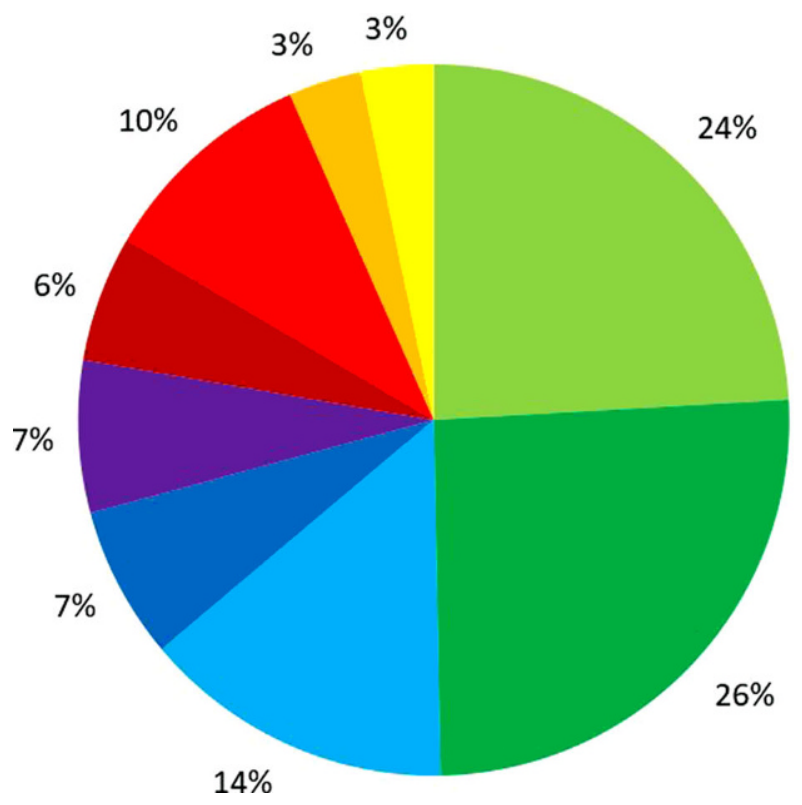

Systemic to targeted

घ Surveillance to targeted

- Change between targeted

- Targeted to systemic

- Surveillance to systemic

- Change between systemic

- Targeted to surveillance

Instemic to surveillance

Other 
Matiollo et al. evaluated the clinical impact of $\left[{ }^{68} \mathrm{Ga}\right]-P S M A$ PET/CT and correlated potential treatment changes to age, Gleason score, PSA level and $\mathrm{SUV}_{\max }$ [30]. A change in treatment was found in 66/104 patients. A significant change of treatment plan was found in patients with a higher Gleason score $(p=0.0233)$, higher $\operatorname{SUV}_{\max }(p=0.0306)$ and higher PSA levels $(p<0.0001$; median PSA $=2.55 \mathrm{ng} / \mathrm{ml})$; however, the clinical consequences of those correlations are not further discussed.

Muller et al. found a substantial increase in the use of metastasis-targeted treatment and a reduction in the use of systemic treatment in all patients imaged during the first year after introduction of $\left[{ }^{68} \mathrm{Ga}\right]-P S M A-$ $11 \mathrm{PET} / \mathrm{CT}$ for BCR into clinical routine [39]. The two most frequently selected therapy options were 'undergoing targeted radiotherapy only' (59/203 included patients; 29\%), and 'undergoing targeted radiotherapy with hormonal therapy' (20/203 patients; $10 \%$ ). The proportion of patients in whom systemic therapy was selected decreased from $60 \%$ (133/223 patients) to $34 \%$ (70/203 patients) based on the information provided by the $\left[{ }^{68} \mathrm{Ga}\right]-P S M A-11$ PET/CT scan. PSMA PET-directed metastasis-targeted treatment led to a complete response after six months in $45 \%$ of patients.

A study by Calais et al. determined how often salvage radiation therapy target volumes based on the Radiation Therapy Oncology Group guidelines covered $\left[{ }^{68} \mathrm{Ga}\right]-P S M A-11$ PET/CT-defined disease, and assessed the potential impact of $\left[{ }^{68} \mathrm{Ga}\right]$-PSMA$11 \mathrm{PET} / \mathrm{CT}$ on salvage radiation therapy in patients with early BCR (PSA $<1.0 \mathrm{ng} / \mathrm{ml}$ ) after radical prostatectomy [25]. They found that 122 of 270 patients (49\%) had a positive $\left[{ }^{68} \mathrm{Ga}\right]-P S M A-11$ PET/CT result. Of these 122 patients, 52 had at least one PSMA positive lesion that was not covered by target volumes, which implied major impact on salvage radiation planning in all of those patients. For 24 patients extension of targeted volumes was possible to cover lymphatic metastases. 22 patients had oligometastatic diseases ( $\leq 5$ metastases), potentially eligible for metastasis directed stereotactic body radiation. Six patients had extensive disease and would be unlikely to profit from salvage radiation therapy.

\section{Discussion}

The included studies in this review all show a substantial impact of PSMA PET on the management of patients with BCR. Some of these studies evaluated whether PSA values were a predictor for therapy change after PSMA PET. Afaq et al. found that higher PSA levels were significantly $(p=0.024)$ associated with management changes; 25.0\%, 26.3\%, 33.3\%, $50.0 \%, 38.5 \%$, and $50.0 \%$ for PSA values $<0.2,0.2-<0.5$, $0.5-<1.0, \quad 1.0<2.0,2.0-<5.0$, and $\geq 5.0 \mathrm{ng} / \mathrm{ml} \mathrm{respec}-$ tively [38]. Mattiolli et al. also found a predictive value of higher PSA levels for change of management $(p<0.0001)$ [30]. In contrast to these findings, Calais et al. found no association between change of management and PSA levels at [ $\left.{ }^{68} \mathrm{Ga}\right]-\mathrm{PSMA}-11$ PET/CT [26]. Hope et al. also found no significant management changes in $42 \%, 40 \%, 65 \%, 57 \%$, and $56 \%$ for PSA values $0-0.2,0.2-1.0,1.0-2.0,2.0-5.0$, and $\geq 5.0 \mathrm{ng} / \mathrm{ml}$, respectively. Furthermore, Roach et al. found no correlation between PSA levels and treatment changes; $67 \%, 60 \%$, and $60 \%$ for PSA levels $<0.2$, $0.2-0.5$, and $>0.5 \mathrm{ng} / \mathrm{ml}$, respectively $[28,32]$. These data show that therapy changes may occur at all PSA levels and possibly even more frequently in patients with higher PSA levels. Therefore, in our opinion, no upper PSA limit should be used to select patients with BCR for PSMA PET/CT. No studies reported whether the character of change of treatment showed any relation with PSA values, since it could be hypothesised that therapy would change more towards systemic strategies in patients with higher PSA levels. Amongst other factors including PSA kinetics, Gleason grade, tumor stage, prior therapy, National Comprehensive Cancer Network risk groups, age and $\mathrm{SUV}_{\max }$ of positive lesions, no other definite predictors of treatment change were found.

None of the included studies in this review provide data on the accuracy of PSMA PET/CT for detection of localisations of BCR. Most data are available from studies that used PSMA PET/CT before salvage lymphadenectomy. The largest of these available studies, by Rauscher et al., retrospectively evaluated 48 patients with biochemical recurrence who underwent $\left[{ }^{68} \mathrm{Ga}\right]-P S M A-11$ PET/CT or PET/MRI [41]. An analysis based on ten defined anatomical fields in the pelvis yielded a sensitivity, specificity, positive predictive value (PPV), negative predictive value (NPV), and accuracy of $78 \%, 97 \%, 95 \%, 88 \%$ and $90 \%$ for PSMA PET and 27\%, 99\%, 95\%, 69\%, and $72 \%$ for morphological imaging (CT or MRI) while a patient based analysis yielded $100 \%, 50 \%, 93 \%, 100 \%$, and 94\% for PSMA PET and 34\%, 83\%, 93\%, 84\%, and 40\% for morphological imaging. Other studies have confirmed these findings, including a meta-analysis by Kimura et al., that showed a high specificity and reasonable sensitivity for lymph node staging (specificity 95-97\% and sensitivity 82-84\%) [42]. Although PSMA PET is more sensitive than morphological imaging, the current sensitivity of PSMA PET/CT is still not high enough to justify salvage lymphadenectomy of solely the PET-positive regions. Furthermore, it remains unclear whether or not salvage lymphadenectomy based on PSMA PET findings will result in better survival outcomes. Siriwardana et al. found a biochemical free survival of $23 \%$ at 12 months after salvage lymph adenectomy in 35 patients with biochemical recurrence after radical prostatectomy with or without previous salvage radiation therapy to the prostate fossa [43].

For other PSMA PET targeted treatments after BCR including salvage radiation therapy to pelvic 


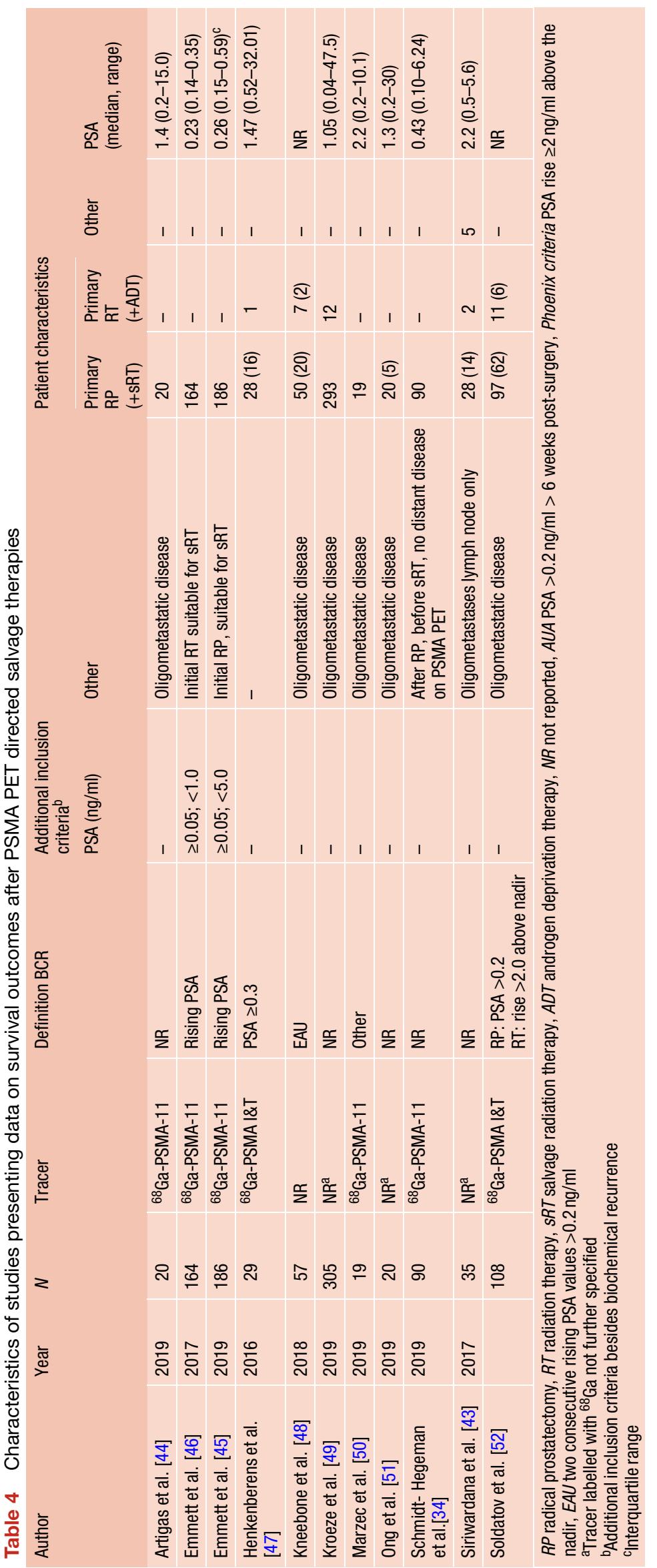




\section{Artikel}

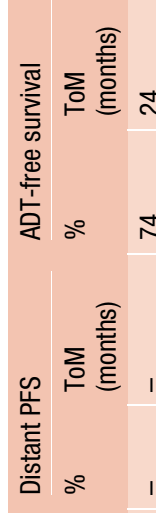

要

$\stackrel{10}{+10}$

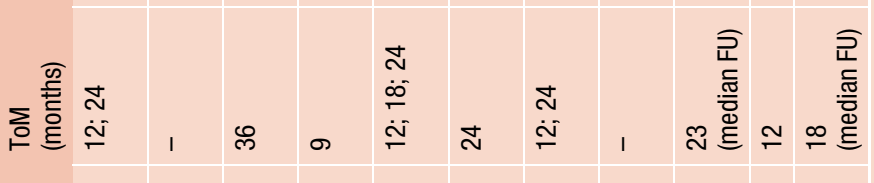

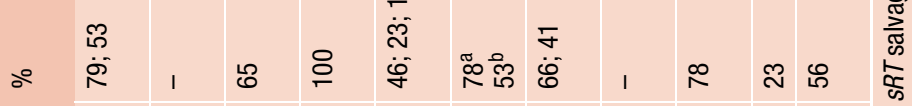

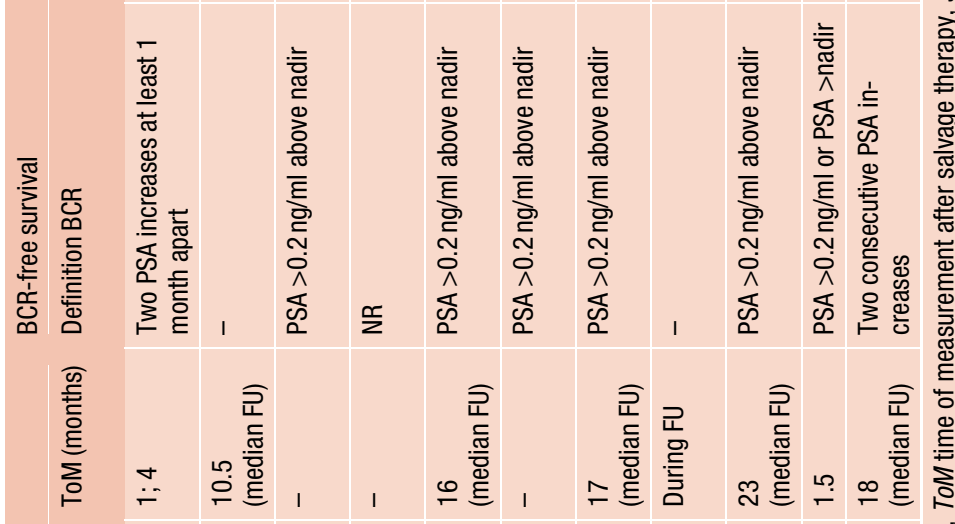

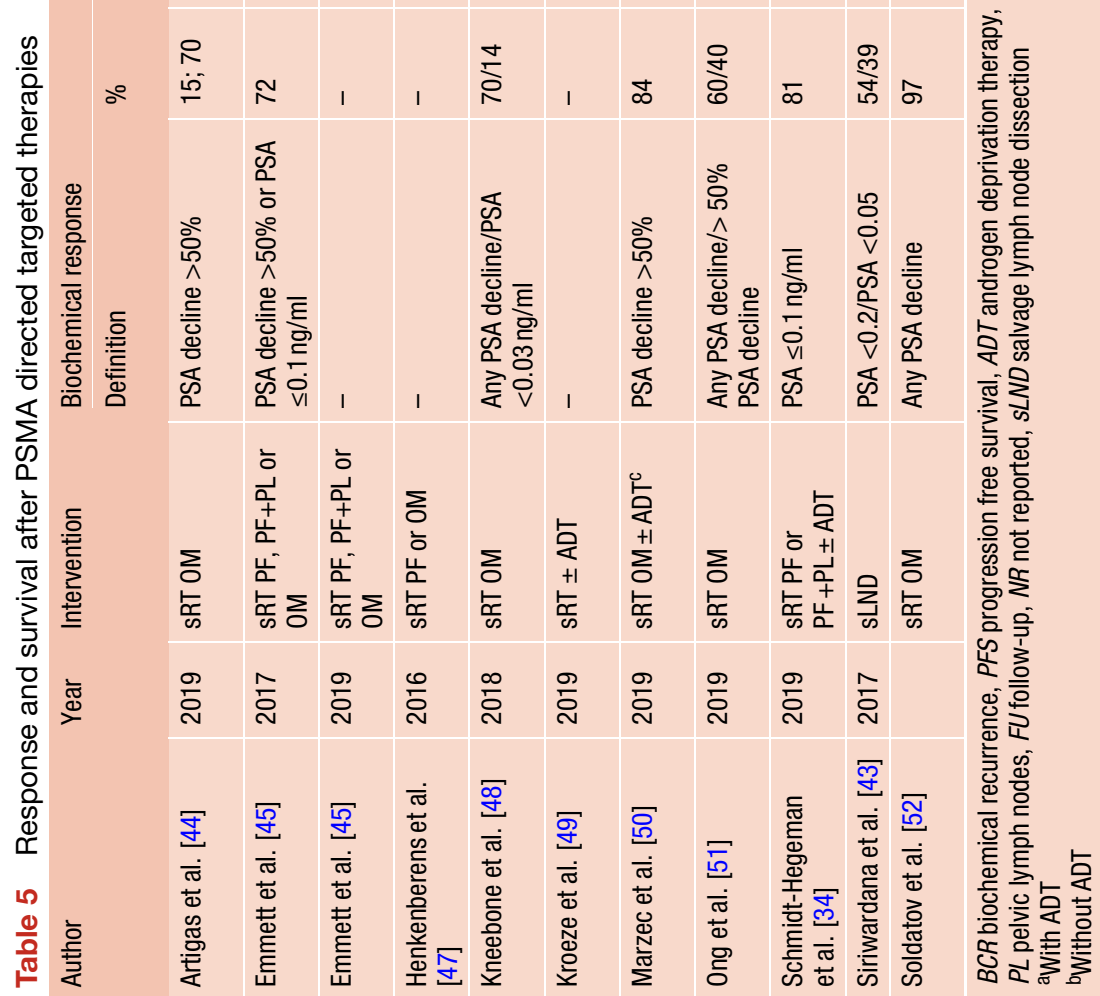


lymph nodes or stereotactic radiation therapy to oligometastatic disease, several studies have analysed survival outcomes of patients treated for BCR after PSMA PET/CT (Tab. 4 and 5) [34, 44-52]. Three studies reported ADT-free survival after salvage radiation therapy for local or oligometastatic disease, which ranged from $70-93 \%$ and $74-83 \%$ at 12 and 24 months, respectively. However, no predefined indications for initiation of ADT were reported. BCRfree survival after salvage radiation therapy was reported in eight studies and ranged between $46-79 \%$ at 12 months (reported in 3 studies) and $16-53 \%$ at 24 months (reported in 4 studies). PSA decline $>50 \%$, reported in four studies, ranged between 40 and $84 \%$. Most studies included heterogenous cohorts including patients that previously underwent radical prostatectomy and/or radiation therapy and with different PSA values at the time of PSMA PET and had a retrospective design. Furthermore, survival outcomes are not uniformly reported in available literature, since definitions of survival outcomes and time points of measurement of these outcomes differ greatly between available studies. None of these studies were properly randomised controlled trials. Therefore, the impact of PSMA PET initiated targeted therapies on survival remains largely unknown.

However, there is some evidence that imaging guided metastasis directed therapy may have effect on survival. A prospective randomized controlled Phase II trial by Ost et al. showed a prolonged median ADT-free survival of 21 months in a group treated with metastasis directed therapy after choline PET/CT (surgery or stereotactic body radiotherapy) compared to 13 months in the surveillance group [53]. These data suggest that metastasis directed therapy should be explored further in randomized clinical trials. An interesting initiative is a randomized prospective phase III trial, in which 193 patients will be randomized 1:1 to standard salvage radiation therapy based on conventional imaging and salvage radiation therapy based on [68Ga]-PSMA-11 PET/CT [54]. The primary end-point of the study will be biochemical progression-free survival, with progression defined by PSA $\geq 0.2 \mathrm{ng} / \mathrm{ml}$ and rising.

\section{Conclusion}

Although high heterogeneity is found between presently available studies, in general, PSMA PET shows promising results as a diagnostic tool in BCR of PCa and induces change of management in almost half of the patients with BCR (45\% pooled data). After PSMA PET more patients are selected for metastasis targeted therapies; however, the potential beneficial effects of metastasis directed therapies, including improved survival outcomes, require further evaluation in prospective randomised clinical trials.
Open Access This article is distributed under the terms of the Creative Commons Attribution 4.0 International License (http://creativecommons.org/licenses/by/4.0/), which permits unrestricted use, distribution, and reproduction in any medium, provided you give appropriate credit to the original author(s) and the source, provide a link to the Creative Commons license, and indicate if changes were made.

\section{References}

1. Siegel RL, Miller KD, Jemal A. Cancer statistics, 2019. CA Cancer JClin. 2019;69:7-34.

2. Ferlay J, Colombet M, Soerjomataram I, Dyba T, Randi G, Bettio M, et al. Cancer incidence and mortality patterns in Europe: estimates for 40 countries and 25 major cancers in 2018. Eur J Cancer. 2018;103:356-87.

3. Cornford P, Bellmunt J, Bolla M, et al. EAU-ESTRO-SIOG Guidelines on prostate cancer. Part II: treatment of relapsing, metastatic, and castration-resistant prostate cancer. Eur Urol. 2017;71:630-42.

4. Amling CL, Bergstralh EJ, Blute ML, Slezak JM, Zincke H. Defining prostate specific antigen progression after radical prostatectomy: what is the most appropriate cut point? JUrol. 2001;165:1146-51.

5. Cookson MS, Aus G, BurnettAL, BurnettAL, EdithD, CanbyHagino ED et al. Variation in the definition of biochemical recurrence in patients treated for localized prostate cancer: the American Urological Association Prostate Guidelines for Localized Prostate Cancer Update Panel report and recommendations for a standard in the reporting of surgical outcomes. JUrol. 2007;177:540-5.

6. Roach M, Marquez C, Yuo HS, Narayan P, Coleman L, Nseyo UO, et al. Predicting the risk of lymph node involvement using the pre-treatment prostate specific antigen and Gleason score in men with clinically localized prostate cancer. Int J Radiat Oncol Biol Phys. 1994;28:33-7.

7. Sokoloff RL, Norton KC, Gasior CL, Marker KM, Grauer LS. A dual-monoclonal sandwich assay for prostate-specific membrane antigen: levels in tissues, seminal fluid and urine. Prostate. 2000;43:150-7.

8. Laidler P, Dulinska J, Lekka M, Lekki J. Expression of prostate specific membrane antigen in androgen-independent prostate cancer cell line PC-3. Arch Biochem Biophys. 2005;435:1-14.

9. Rajasekaran SA, Anilkumar G, Oshima E, Bowie JU, Liu H, Heston W. A novel cytoplasmic tail MXXXL motif mediates the internalization of prostate-specific membrane antigen. MolBiolCell. 2003;14:4835-45.

10. Elsasser-Beile U, Wolf P, Gierschner D, Buhler P, SchultzeSeemannW, Wetterauer U.Anewgeneration of monoclonal and recombinant antibodies against cell-adherent prostate specific membrane antigen for diagnostic and therapeutic targeting of prostate cancer. Prostate. 2006;66:1359-70.

11. Tagawa ST, Beltran H, Vallabhajosula S, Goldsmith SJ, Osborne J, Matulich D, etal. Anti-prostate-specific membrane antigen-based radioimmunotherapy for prostate cancer. Cancer. 2010;116:1075-83.

12. WolfP, Freudenberg N, Buhler P, etal. Three conformational antibodies specific for different PSMA epitopes are promising diagnostic and therapeutic tools for prostate cancer. Prostate. 2010;70:562-9.

13. Regino CA, Wong KJ, MilenicDE, Williams M, Garmestani K, Brechbiel MW, et al. Preclinical evaluation of a monoclonal antibody (3C6) specific for prostate-specific membrane antigen. Curr Radiopharm. 2009;2:9-17.

14. Foss CA, Mease RC, Fan H, Wang Y, Ravert HT, Dannals RF, et al. Radiolabeled small-molecule ligands for prostate- 
specific membrane antigen: in vivo imaging in experimental models of prostate cancer. Clin Cancer Res. 2005;11:4022-8.

15. Mease RC, Dusich CL, Foss CA, Ravert HT, Dannals RF, al Seidel Jet. N-[N-[(S)-1,3-Dicarboxypropyl]carbamoyl]4-[18F]fluorobenzyl-L-cysteine, [18F]DCFBC: a new imaging probe for prostate cancer. Clin Cancer Res. 2008;14:3036-43.

16. Chen Y, Pullambhatla M, Foss CA, Byun Y, Nimmagadda S, Senthamizhchelva S. 2-(3-\{1-Carboxy-5-[(6-[18F]fluoropyridine-3-carbonyl)-amino]-pentyl\}-ureido)-pen tanedioic acid, [18F]DCFPyL, a PSMA-based PET imaging agent for prostate cancer. Clin Cancer Res. 2011;17:7645-53.

17. Afshar-Oromieh A, Zechmann CM, Malcher A, Eder M, Eisenhut M, Linhart HG, et al. Comparison of PET imaging with a (68)Ga-labelled PSMA ligand and (18)F-cholinebasedPET/CTforthediagnosis of recurrent prostatecancer. Eur J Nucl Med Mol Imaging. 2014;41:11-20.

18. Bluemel C, Krebs M, Polat B, Linke F, Eiber M, Samnick S, et al. 68Ga-PSMA-PET/CT in patients with biochemical prostate cancer recurrence and negative 18F-CholinePET/CT. Clin Nucl Med. 2016;41:515-21.

19. Giesel FL, Knorr K, Spohn F, Will L, Maurer T, Flechsig P, et al. Detection efficacy of [(18)F]PSMA-1007 PET/CT in 251 Patients with biochemical recurrence after radical prostatectomy. J Nucl Med. 2019;60(3):362-8.

20. Mena E, Lindenberg ML, Turkbey IB, Shih DH, Harmon SA, Lim I, et al. (18)F-DCFPyL PET/CT imaging in patients with biochemical recurrence prostate cancer after primary local therapy. J Nucl Med. 2020;61(6):881-9.

21. Perera M, Papa N, Roberts M, Williams M, Udovicich C, Vela I, et al. Gallium-68 prostate-specific membrane antigen positron emission tomography in advanced prostate cancer-updated diagnostic utility, sensitivity, specificity, and distribution of prostate-specific membrane antigenavid lesions: a systematic review and meta-analysis. Eur Urol. 2020;77(4):403-17.

22. Rahbar K, Afshar-Oromieh A, Seifert R, Wagner S, Schäfers M, Bögemann M, et al. Diagnostic performance of (18)F-PSMA-1007 PET/CT in patients with biochemical recurrent prostate cancer. Eur J Nucl Med Mol Imaging. 2018;45:2055-61.

23. Wondergem M, Jansen BHE, van der Zant FM, van der Sluis TM, Knol RJJ, van Kalmthout LWM, et al. Early lesion detection with (18)F-DCFPyL PET/CT in 248 patients with biochemically recurrent prostate cancer. Eur J Nucl Med Mol Imaging. 2019;46:1911-8.

24. Bashir U, Tree A, Mayer E, Levine D, Parker C, Dearnaley D, et al. Impact of Ga-68-PSMA PET/CT on management in prostate cancer patients with very early biochemical recurrence after radical prostatectomy. Eur J Nucl Med Mol Imaging. 2019;46(4):901-7.

25. Calais J, Czernin J, Cao M, et al. (68)ga-PSMA-11 PET/CT mapping of prostate cancer biochemical recurrence after radical prostatectomy in 270 patients with a PSAlevel of less than $1.0 \mathrm{ng} / \mathrm{mL}$ : impact on salvage radiotherapy planning. J Nucl Med. 2018;59:230-7.

26. Calais J, Fendler WP, Eiber M, et al. Impact of (68)Ga-PSMA$11 \mathrm{PET} / \mathrm{CT}$ on the Management of Prostate Cancer Patients with Biochemical Recurrence. J Nucl Med. 2018;59:434-41.

27. Grubmuller B, Baltzer P, D'Andrea D, et al. (68)Ga-PSMA 11 ligandPETimaging in patients with biochemical recurrence after radical prostatectomy-diagnostic performance and impact on therapeutic decision-making. Eur J Nucl Med Mol Imaging. 2018;45:235-42.
28. Hope TA, Aggarwal R, Chee B, et al. Impact of (68)ga-PSMA11 PET on management in patients with biochemically recurrent prostate cancer. J Nucl Med. 2017;58:1956-61.

29. Kulkarni M, Hughes S, Mallia A, et al. The management impact of (68)gallium-tris(hydroxypyridinone) prostatespecific membrane antigen ((68)Ga-THP-PSMA) PET-CT imaging for high-risk and biochemically recurrent prostate cancer. Eur J Nucl Med Mol Imaging. 2020;47:674-86.

30. Mattiolli AB, Santos A, Vicente A, et al. Impact of 68GAPSMA PET / CT on treatment of patients with recurrent / metastatic high risk prostate cancer-a multicenter study. Int Braz J Urol. 2018;44:892-9.

31. Mena E, Lindenberg ML, Shih JH, et al. Clinical impact of PSMA-based (18)F-DCFBC PET/CT imaging in patients with biochemically recurrent prostate cancer after primary local therapy. Eur J Nucl Med Mol Imaging. 2018;45:4-11.

32. Roach PJ, Francis R, Emmett L, et al. The impact of (68)ga-PSMA PET/CT on management intent in prostate cancer: results of an Australian prospective multicenter study. J Nucl Med. 2018;59:82-8.

33. Rousseau C, Le Thiec M, Ferrer L, et al. Preliminary results of a (68) Ga-PSMA PET/CT prospective study in prostate cancer patients with occult recurrence: diagnostic performance and impact on therapeutic decision-making. Prostate. 2019;79:1514-22.

34. Schmidt-Hegemann NS, Stief C, et al. Outcome after PSMA PET/CT based salvage radiotherapy in patients with biochemical recurrence after radical prostatectomy: a biinstitutional retrospective analysis. J Nucl Med. 2018; https://doi.org/10.2967/jnumed.118.212563.

35. Song $\mathrm{H}$, Harrison C, Duan $\mathrm{H}$, et al. Prospective evaluation in an academic center of (18)F-DCFPyL PET/CT in biochemically recurrent prostate cancer: a focus on localizing disease and changes in management. J Nucl Med. 2019; https:// doi. org/10.2967/jnumed.119.231654.

36. Zacho HD, Nielsen JB, Dettmann K, et al. 68Ga-PSMA PET/CT in Patients With Biochemical Recurrence of Prostate Cancer: A Prospective, 2-Center Study. Clin Nucl Med. 2018;43:579-85.

37. FarolfiA, CeciF, CastellucciP, etal. (68)Ga-PSMA-11 PET/CT in prostate cancer patients with biochemical recurrence after radical prostatectomy and PSA. Eur J Nucl Med Mol Imaging. 2019;46(1):11-19.

38. Afaq A, Alahmed S, Chen SH, et al. Impact of (68)gaprostate-specific membrane antigen $\mathrm{PET} / \mathrm{CT}$ on prostate cancer management. J Nucl Med. 2018;59:89-92.

39. Muller J, Ferraro DA, Muehlematter UJ, etal. Clinical impact of (68)Ga-PSMA-11 PET on patient management and outcome, including all patients referred for an increase in PSA level during the first year after its clinical introduction. Eur J Nucl Med Mol Imaging. 2019;46:889-900.

40. Hope TA, Truillet C, Ehman EC, et al. 68ga-PSMA-11 PET imaging of response to androgen receptor inhibition: first human experience. J Nucl Med. 2017;58:81-4.

41. Rauscher I, Maurer T, Beer AJ, et al. Value of 68gaPSMA HBED-CC PET for the assessment of lymph node metastases in prostate cancer patients with biochemical recurrence: comparison with Histopathology after salvage Lymphadenectomy. J Nucl Med. 2016;57:1713-9.

42. Kimura S, Abufaraj M, Janisch F, et al. Performance of [(68)Ga] Ga-PSMA 11 PET for detecting prostate cancer in the lymph nodes before salvage lymph node dissection: a systematic review and meta-analysis. Prostate Cancer Prostatic Dis. 2020;23:1-10.

43. Siriwardana A, Thompson J, van Leeuwen PJ, et al. Initial multicentre experience of (68) gallium-PSMA PET/CT guided robot-assisted salvage lymphadenectomy: accept- 
able safety profile but oncological benefit appears limited. BJU Int. 2017;120:673-81.

44. Artigas C, Flamen P, Charlier F, et al. (68)Ga-PSMA PET/CTbased metastasis-directed radiotherapy for oligometastatic prostate cancer recurrence after radical prostatectomy. World J Urol. 2019;37:1535-42.

45. Emmett L, Tang R, Nandurkar RH, et al. 3-year freedom from progression following (68)GaPSMA PET CT triaged management in men with biochemical recurrence post radical prostatectomy. Results of a prospective multicenter trial. J Nucl Med. 2019; https://doi.org/10.2967/ jnumed.119.235028.

46. Emmett L, van Leeuwen PJ, Nandurkar R, et al. Treatment outcomes from (68)ga-PSMA PET/CT-informed salvage radiation treatment in men with rising PSA after radical prostatectomy: prognostic value of a negative PSMA PET. J Nucl Med. 2017;58:1972-6.

47. Henkenberens C, von Klot CA, Ross TL, et al. (68)Ga-PSMA ligand PET/CT-based radiotherapy in locally recurrent and recurrent oligometastatic prostate cancer : Early efficacy after primary therapy. Strahlenther Onkol. 2016;192:431-9.

48. Kneebone A, Hruby G, Ainsworth H, et al. Stereotactic body radiotherapy for oligometastatic prostate cancer detected via prostate-specific membrane antigen positron emission tomography. Eur UrolOncol. 2018;1:531-7.

49. Kroeze SGC, Henkenberens C, Schmidt-Hegemann NS, et al. Prostate-specific membrane antigen positron emission tomography-detected oligorecurrent prostate cancer treated with metastases-directed radiotherapy: role of addition and duration of androgen deprivation. Eur Urol Focus. 2019; https://doi.org/10.1016/j.euf.2019.08.012.

50. Marzec J, Becker J, Paulsen F, et al. (68)Ga-PSMAPET/CT-directed IGRT/SBRT for oligometastases of re- current prostate cancer after initial surgery. Acta Oncol. 2020;59:149-56.

51. Ong WL, Koh TL, Lim Joon D, et al. Prostate-specific membrane antigen-positron emission tomography/computed tomography (PSMA-PET/CT)-guided stereotactic ablative body radiotherapy for oligometastatic prostate cancer: a single-institution experience and review of the published literature. BJU Int. 2019; https://doi.org/10.1111/ bju.14886.

52. Soldatov A, von Klot CAJ, Walacides D, et al. Patterns of progression after (68)ga-PSMA-ligand PET/CT-guided radiation therapy for recurrent prostate cancer. Int J Radiat Oncol Biol Phys. 2019;103:95-104.

53. Ost P, Reynders D, Decaestecker K, et al. Surveillance or metastasis-directed therapy for oligometastatic prostate cancer recurrence: a prospective, randomized, multicenter phase II trial. JClin Oncol. 2018;36:446-53.

54. Calais J, Czernin J, Fendler WP, Elashoff D, Nickols NG. Randomized prospective phase III trial of (68)Ga-PSMA$11 \mathrm{PET} / \mathrm{CT}$ molecular imaging for prostate cancer salvage radiotherapy planning [PSMA-SRT. BMC Cancer. 2019; https://doi.org/10.1186/s12885-018-5200-1.

Maurits Wondergem, nuclear medicine physician

Friso M. van der Zant, nuclear medicine physician

Wouter A.M. Broos, nuclear medicine physician

Remco J.J. Knol, nuclear medicine physician 